\title{
Freshwater planarians from artesian springs in Queensland, Australia (Platyhelminthes, Tricladida, Paludicola)
}

\author{
Ronald Sluys ${ }^{1}$, Lauryne J. Grant ${ }^{2}$ and David Blair ${ }^{2}$ \\ ${ }^{1}$ Institute for Biodiversity and Ecosystem Dynamics \& Zoological Museum, University of Amsterdam, P.O. Box \\ 94766, 1090 GT Amsterdam, The Netherlands, e-mail sluys@science.uva.nl; ${ }^{2}$ School of Tropical Biology, James \\ Cook University, Townsville, Queensland 4811, Australia
}

Key words: artesian springs, Australia, Dugesiidae, Platyhelminthes, Tricladida, Dugesia, Weissius

\begin{abstract}
Two new species of triclad flatworm are described from artesian springs in Queensland, Australia, viz. Dugesia artesiana Sluys and Grant, sp. nov. and Weissius capaciductus Sluys, gen. et sp. nov. Some historical biogeographic scenarios are discussed that may explain the occurrence of the new species and their close relatives in Australia.
\end{abstract}

\section{Contents}

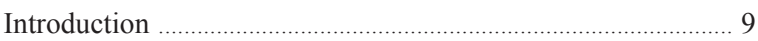

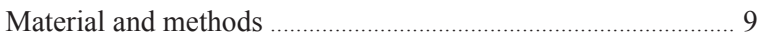

Systematic section .................................................................... 9

Genus Dugesia Girard, 1850 .................................................... 9

Genus Weissius Sluys, gen nov. ............................................. 12

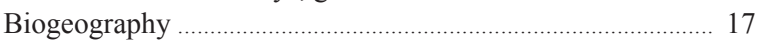

Acknowledgements ..................................................................... 18

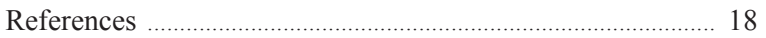

\section{Introduction}

Although the commencement of studies on the freshwater planarians of Australia dates back as far as the beginning of the $20^{\text {th }}$ century (cf. Weiss, 1909, 1910), our knowledge on the biodiversity of these animals on the Australian continent is still in its infancy. Only very recently major studies were undertaken that aimed to document the diversity and biogeography of Australian paludicolans (Sluys and Kawakatsu, 2001; Grant et al., 2006), some decades after the publications of another student of Australian triclads (Ball, 1974, 1977; Ball and Tran, 1979).

The present paper describes for the first time the planarian fauna of artesian springs associated with the Great Artesian Basin, the major part being located in Queensland. These springs, located in otherwise arid regions, provide a unique habitat for a variety of endemic invertebrates. Notably hydrobiid snails have radiated in these artesian springs (Ponder et al., 1989; Ponder and Clark, 1990). In this paper we describe two new species of freshwater planarian, the first ones to be reported from an artesian habitat in Australia.

\section{Material and methods}

Animals were initially fixed in formalin but were postfixed in Steinmann's fluid. Serial sections were made at intervals of 5 or $8 \mu \mathrm{m}$. The sections, prior to staining, were treated by an acidic dichrome mordant solution and were subsequently stained in Martius Scarlet Blue (cf. Bradbury and Gordon, 1977). The material is deposited in the Australian Museum, Sidney (AM), the Queensland Museum, Brisbane (QM) and the Zoological Museum Amsterdam (ZMA).

Abbreviations used in the figures: amp, ampulla; at, atrium; bc, bursal canal; ca, common atrium; cb, copulatory bursa; $\mathrm{cp}$, ciliated pit; dp, diaphragm; ed, ejaculatory duct; go, gonopore; ma, male atrium; od, oviduct; ov, ovary; pb, penis bulb; pg, penis glands; ph, pharynx; pp, penis papilla; sg, shell glands; spe, spermatophore; sv, seminal vesicle; te, testis; vd, vas deferens; vf, valve-like fold, vnc, ventral nerve cord.

\section{Systematic section}

Suborder Tricladida Lang, 1884

Infraorder Paludicola Hallez, 1892

Family Dugesiidae Ball, 1974

Genus Dugesia Girard, 1850

Dugesia artesiana Sluys and Grant, sp. nov.

Material examined.- Holotype: AM W.29441, Edgbaston Sta-

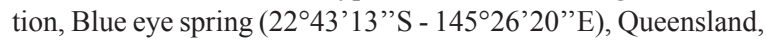
Australia, 6 October 2002, coll. W.F. Ponder and A. Davis, sagittal sections on 12 slides. 
Additional material: ZMA V.P1. 3054.1, Edgbaston Station, spring 12, at spring head $\left(22^{\circ} 45^{\prime} 20^{\prime \prime} \mathrm{S}-145^{\circ} 25^{\prime} 31^{\prime \prime} \mathrm{E}\right)$, Queensland, Australia, 6 October 2002, coll. W.F. Ponder, J.H. Waterhouse, and A.C. Miller, sagittal sections on 21 slides.

Etymology.- The specific epithet is derived from the English adjective "artesian" and alludes to the fact that the animals have been collected from the artesian system in the Great Artesian Basin.

Diagnosis.- Dugesia artesiana is characterized by a presumably central ejaculatory duct, asymmetrical openings of the oviducts into the bursal canal, infranucleated bursal canal, absence of ectal reinforcement, small diaphragm, and absence of a duct between intrabulbar seminal vesicle and diaphragm.

Ecology and distribution.- The holotype was collected from shallow water at the spring's edge, and the other specimen was found in a flowing seepage at the head of another spring. The species is known only from these two springs in the Great Artesian Basin at Edgbaston, which are separated by a distance of about $8 \mathrm{~km}$.

Description.- Preserved specimens up to $14 \mathrm{~mm}$ long and $2 \mathrm{~mm}$ wide. Dorsally a light yellow-brown base is consistent throughout all specimens, yet the density of

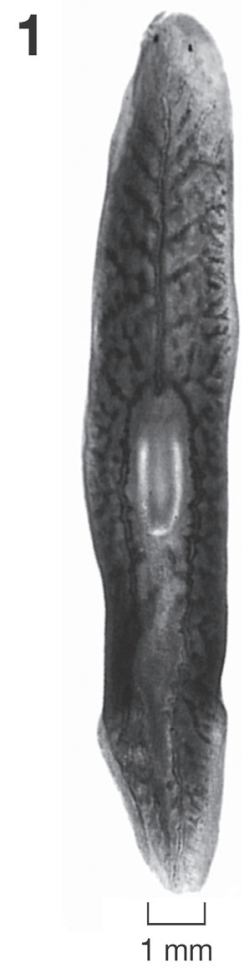

Fig. 1. Dugesia artesiana. Dorsal view of preserved specimen.

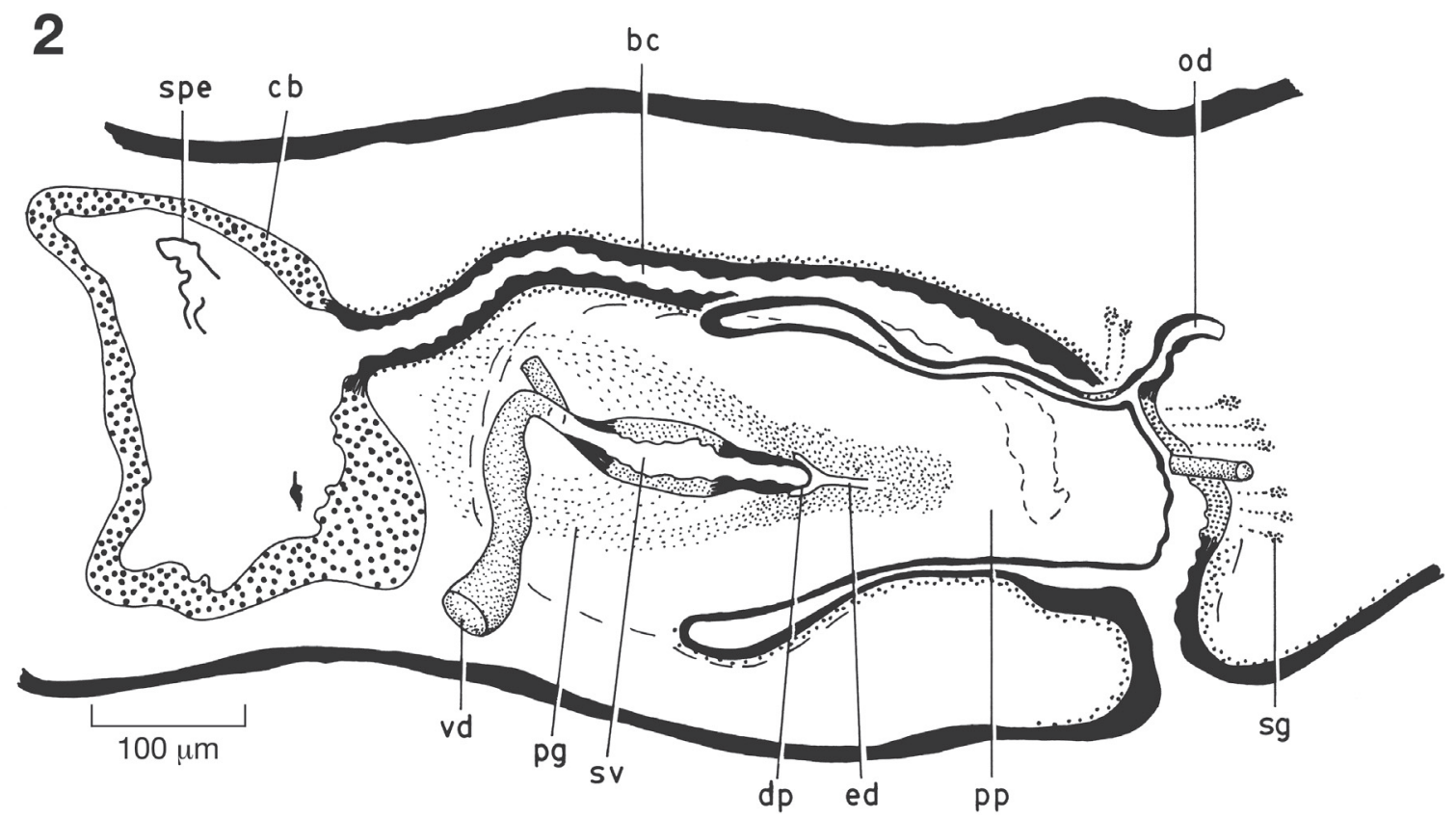

Fig. 2. Dugesia artesiana. Holotype. Sagittal reconstruction of the copulatory apparatus. Anterior to the left. 
the fine dark specks varies. Consequently, dorsal pigmentation ranges from dark brown to light yellowbrown. However, regardless of the level of pigmentation it always lightens considerably at the body margins and over the pharyngeal region. Likewise the ventral surface is always paler than dorsal, as pigment is less intense. Examination of the histological sections revealed that the dorsal surface of the holotype is densely pigmented, whereas pigment granules appeared to be absent or very sparse underneath the dorsal epidermis of the other specimen. In the preserved state the front end is rounded (Fig. 1), with no evidence of auricles, owing to preservation effects. A pair of small, pigmented eye cups sit at the point where head tapers in, and positioned closer to each other than to lateral margins. No other sensory structures are evident. The pharynx is positioned posteriorly, in most cases, occupying between one-fourth and one-fifth of the total body length. In the highly contracted holotype and in specimen V.Pl. 3054.1 the pharynx is located in the middle of the body and measures between $1 / 5-1 / 6^{\text {th }}$ and $1 / 8-1 / 9^{\text {th }}$ of the body length, respectively. The mouth opening is located at the posterior end of the pharyngeal pocket.

The small testes are situated dorsally and extend from the level of the ovaries, or slightly anterior to the female gonads, to well beyond the copulatory apparatus. The ovaries are located at about $1 / 3^{\text {rd }}$ of the distance between the brain and the root of the pharynx. The oviducts arise from the dorsal surface of the ovarial wall, with these proximal ends of the ducts being much wider than the major part of the oviducts traversing the body; the oviducts do not branch, i.e. they do not extend backwards beyond the level of the copulatory apparatus.

The sperm ducts communicate separately with the very proximal, anterior section of an elongated, intrabulbar seminal vesicle. The latter is lined with a relatively tall epithelium, receiving the secretion of erythrophilic penis glands. The distal, posterior end of the vesicle tapers to form a small diaphragm conus, which receives the abundant secretion of erythrophilic penis glands. The diaphragm conus projects into the funnelshaped, proximal section of the ejaculatory duct, the latter receiving the secretion of the erythrophilic penis glands. It is difficult to ascertain whether the ejaculatory duct runs a central or an acentral, ventrally displaced course through the penis papilla. In the holotype the ejaculatory duct could be traced for only part of its length, while its opening at the tip of the penis papilla is not apparent (Fig. 2). In specimen V.Pl. 3054.1 the ejaculatory duct runs a central course through the penis, with a clear opening at the tip. However, in this animal the penis papilla is highly contracted, which may have resulted in an artefactual condition with regard to the course of the ejaculatory duct (Fig. 3). The penis papilla is covered with a nucleated epithelium.

The bursal canal arises from the lateral wall of the common atrium and runs anteriad latero-dorsally to the male atrium and the penis bulb. Immediately anterior to the bulb, the bursal canal communicates with the sac-shaped copulatory bursa. In the holotype the

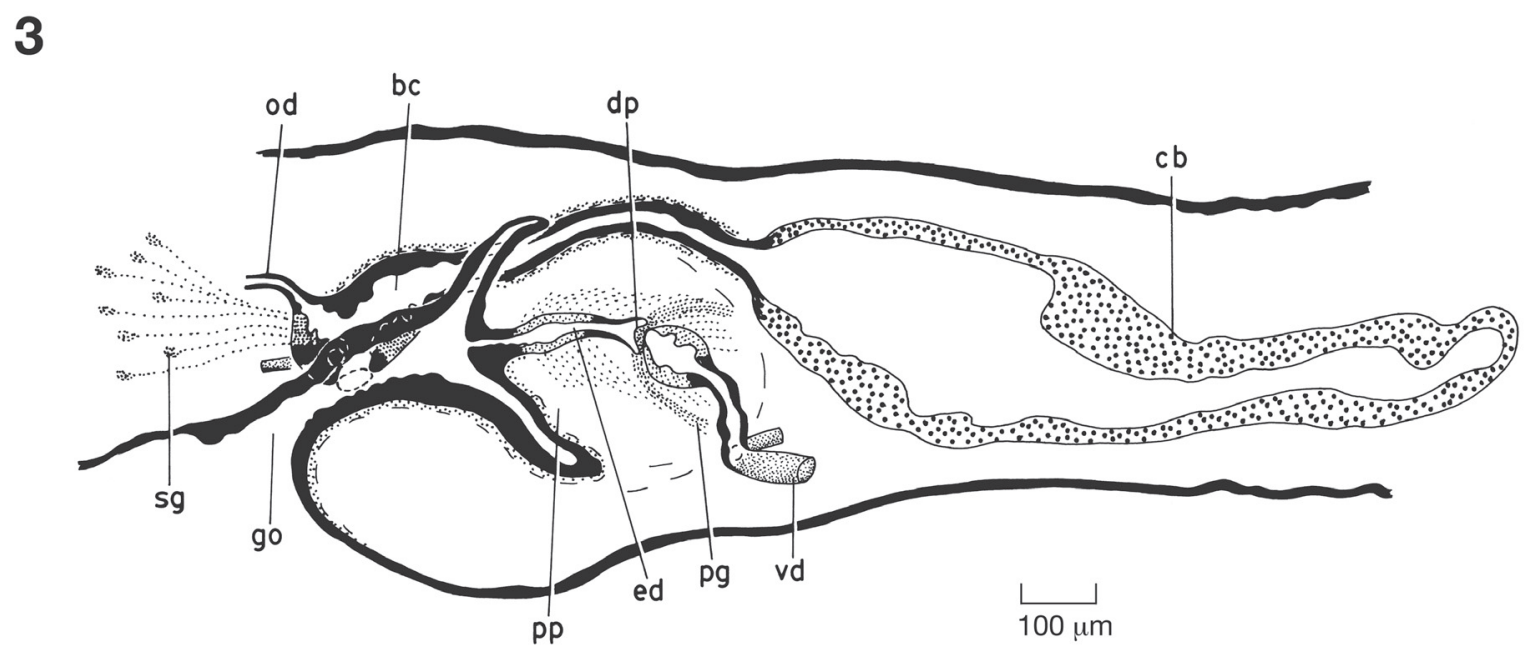

Fig. 3. Dugesia artesiana. ZMA V.P1. 3054.1. Sagittal reconstruction of the copulatory apparatus. Anterior to the right. 
bursa contains remnants of a spermatophore. The bursal canal receives the asymmetrical openings of the infranucleated oviducts very close to the junction with the common atrium. One oviduct opens into the postero-ventral section of the bursal canal, or even into the atrium itself, whereas the other oviduct approaches the canal from a more ventro-lateral direction. Shell glands open into the ventral section of the bursal canal, i.e. in the region where the canal receives the openings of the oviducts. The bursal canal is lined with an infranucleated epithelium for most of its length; in specimen V.Pl. 3054.1 only a short section of the bursal canal immediately adjacent to the copulatory bursa is provided with nucleated cells. The most prominent muscle layer around the bursal canal is one consisting of circular muscle. However, in specimen V.Pl. 3054.1 a thin subepithelial layer of longitudinal muscle is also present; this layer of longitudinal muscle could not be traced in the holotype.

Discussion.- Apart from the problematic Dugesia(?) rava (Weiss, 1909) (cf. Grant et al., 2006), only one other species of Dugesia has been described for Australia, viz. D. notogaea Sluys and Kawakatsu, 1998 (Sluys et al., 1998) from northern Queensland. The latter shows several features in which it differs from $D$. artesiana: hyperplastic ovaries; testes that begin at a short distance behind the brain; large, thin-walled seminal vesicle; relatively long duct between seminal vesicle and diaphragm; distinctly acentral ejaculatory duct. In our opinion these differences indicate that the worms from the Edgbaston locality are essentially different from D. notogaea, which occurs also in northern Queensland.

With respect to other, non-Australian species of Dugesia, the following species share with $D$. artesiana the presence of both a small diaphragm and the absence of a duct between seminal vesicle and diaphragm: D. aethiopica, D. bactriana, D. biblica, $D$. colapha, D. debeauchampi, D. didiaphragma, D. indica, D. lamottei, D. lanzai, D. leclerci, D. nannophallus, D. nanshae, D. neumanni, D. sicula. Distinct anatomical features differentiate most of these species from $D$. artesiana, excepting five species for which anatomical resemblance to $D$. artesiana at first sight is much greater, viz. D. biblica, D. colapha, D. indica, $D$. leclerci, and D. neumanni. However, in D. biblica and $D$. neumanni the bursal canal is provided with distinct ectal reinforcement muscles that extend from the vaginal area to the copulatory bursa; ectal reinforcement is absent in D. artesiana. In D. colapha and
D. indica the bursal canal is nucleate, in contrast to the infranucleated canal in $D$. artesiana. For the rest, the simple copulatory apparatuses of $D$. colapha and $D$. indica resemble much that of $D$. artesiana. However, in $D$. indica the penis papilla is clearly asymmetrical, in contrast to the other two species. Furthermore, in the African species, D. colapha, the outer pharynx musculature consists of three layers, a condition that is absent in D. artesiana and $D$. indica, which show the more common two-layered condition.

\section{Genus Weissius Sluys, gen. nov.}

Diagnosis.- Dugesiidae with a ciliated pit on either side of the head and with the copulatory apparatus located in the most posterior part of the body, close to the posterior body margin. Testes ventral and prepharyngeal. Small ovaries directly behind the brain. Anterior sections of the oviducts gradually expanding to form a spacious ampulla communicating with the ovary. Finger-shaped, short penis papilla. Penis bulb elongated, consisting of circular muscle, housing an elongate seminal vesicle, which receives the separate openings of the sperm ducts and the secretion of two types of erythrophilic penis glands. Male and common atrium covered by a well-developed layer of circular muscle and a broad, ball-shaped zone of longitudinal muscle, with some of these fibres attaching around the gonopore. Common atrium with a valvelike constriction before communicating with the gonopore. Oviducts separately enter the bursal canal well above the zone of shell glands. Bursal canal covered with layer of circular muscle and communicating with copulatory bursa. Sperm transfer through exchange of spermatophore.

Etymology.- In conformity with the fact that most of the current generic names in the Dugesiidae are derived from names of planarian workers, the genus is named for Annie Weiss in recognition of her early contribution to our knowledge of Australian freshwater planarians. Gender: masculine.

Weissius capaciductus Sluys, sp. nov.

Material examined.- Holotype: AM W.29442, Bundoona Station (Eulo station 15B), main spring, main flow area (2757'120”S - 14446'150”E), Queensland, Australia, 4 April 2002, sagittal sections on 6 slides. Paratypes: QM: G 225677, ibid., sagittal sections on 8 slides; ZMA V.Pl. 3055.1, ibid., sagittal sections 
on 7 slides; AM W.29443, ibid., horizontal sections on 3 slides; ZMA V.Pl. 3055.2, ibid., horizontal sections on 3 slides; QM G 225678, ibid., horizontal sections on 3 slides.

Additional material: AM W.29444, Bundoona Station (station no.: Eulo 15A1) (2757'07'S - 14446'09'E), Queensland, Australia, 4 April 2002, sagittal sections on 6 slides; ZMA V.Pl. 3056.1, ibid., sagittal sections on 7 slides; ZMA V.P1. 3056.2, ibid., horizontal sections on 3 slides; AM W.29445, ibid., sagittal sections on 5 slides; AM W.29446, ibid., sagittal sections on 4 slides. ZMA V.Pl. 3057, Bundoona Station (station no.: Eulo 29A), west of road to Quilpie, pool nearest to creek (2756'29' S - 14446'42'E), Queensland, Australia, 6 April 2002, preserved specimens; ZMA V.P1. 3057.1, ibid., sagittal sections on 5 slides; AM W.29447, ibid., sagittal sections on 8 slides.

QM: G 225679, Bundoona Station (station no.: Eulo 15A) (2757'07'S - 14446'09''E), Queensland, Australia, 4 April 2002, sagittal sections on 5 slides; G 225680, ibid., sagittal sections on 3 slides; G 225681, ibid., sagittal sections on 4 slides; G 225682, ibid., sagittal sections on 6 slides; G 225683, ibid., sagittal sections on 5 slides. ZMA V.P1. 3058.1, Bundoona Station (station no.: Eulo 29D) (2756'29''S - 14446'42'"E), Queensland, Australia, 6 April 2002, sagittal sections on 5 slides; AM W.29448, ibid., horizontal sections on 3 slides. ZMA V.Pl. 3059.1, Bundoona Station (station no.: Eulo 29B)

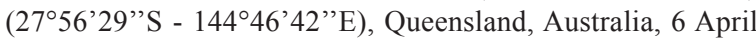
2002, 1 whole mount on 1 slide; AM W.29449, ibid., 1 whole mount on 1 slide; QM G225684, ibid., 1 whole mount on 1 slide. AM W29023, Bundoona Station (station no.: Eulo 16A) (2756'56'S - 14446'23'E), 4 April 2002, preserved specimens.

QM: G225685, Bundoona Station (station no.: Eulo 15/1A) (275'07'"'S - 14446'09'E), 4 April 2002, preserved specimens.

All samples were collected by W.F. Ponder, J.H. Waterhouse, and A.C. Miller.

Etymology.- The specific epithet is derived from the Latin adjective "capax", spacious, and the noun "ductus"; it alludes to the situation that particularly the anterior section of each oviduct is expanded to form a well-developed ampulla.

Diagnosis.- With the characteristics of the genus.

Ecology and distribution.- All samples were taken in a small group of coalescing springs on Bundoona Station, near the homestead, with the specimens from samples W.29444-6, V.P1. 3056, W.29442-3, G2256778, and V.Pl. 3055 having been collected on the same day from various locations at the largest spring. Samples V.Pl. 3057, W.29447, V.Pl. 3059, W.29449, G225684,V.Pl. 3058.1, W.29448, W.29023, and G225685 were taken at several different pools within $100 \mathrm{~m}$ from the largest spring. At most of these sites animals were collected from wet sand and mud and on vegetation out of the water flow or from seepage areas of the springs, with short sedges and duck weed.

Description.- Preserved specimens up to $5 \mathrm{~mm}$ long and $1 \mathrm{~mm}$ wide. Light base with darker pigment speckled throughout, concentrating particularly around the pharynx, giving an overall dark brown appearance. This dark pigment is much sparser on the ventral surface, leaving the light base exposed with a resulting paler appearance. In its preserved state the animal exhibits a broad round head and tail. Eyes absent. An unpigmented ciliated pit is located on either side of the head, slightly anterior to the brain and rather close to the margin of the body (Figs 4, 5). Each relatively deep pit is made up of invaginated, nucleated epidermal cells, which are devoid of rhabdites and are provided with long cilia (Fig. 6).

The unpigmented pharynx is always positioned entirely in the posterior half of the animal (Fig. 4), occupying between $1 / 4-1 / 6^{\text {th }}$ of total body length in preserved specimens. The mouth opens at the most posterior extent of the pharyngeal pocket.

The testes are situated ventrally, extending from some distance behind the brain and the ovaries up to the root of the pharynx (Fig. 7). The small ovaries are located directly behind the brain. For such a small animal, the oviducts are rather thick tubes, lined with cuboidal or rectangular, nucleated cells. In addition, the anterior sections of the oviducts are developed to even greater extent since these parts gradually widen to give rise to a spacious ampulla, frequently containing sperm (Fig. 8). Surprisingly, the ampulla appears to communicate with the dorsal section of the ovary, with this part of the female gonad containing the germ centre.

The vasa deferentia are swollen to form spermiducal vesicles. In the proximity of the penis bulb, the sperm ducts narrow considerably and are surrounded by a distinct layer of circular muscle. The sperm ducts open separately into the anteriormost part of the elongated intrabulbar seminal vesicle, the latter communicating with the relatively broad ejaculatory duct. There is a distinct constriction at the point where the seminal vesicle opens into the ejaculatory duct, i.e. at the level of the root of the penis papilla. The section of the seminal vesicle adjacent to this point of communication receives the openings of penis glands producing a coarsegrained, orange-brown secretion. Another type of penis gland, producing a red and slightly more fine-grained secretion, discharges into the anterior part of the seminal vesicle. This vesicle is surrounded by a thick coat of circular muscle, thus constituting the penis bulb. 
The short penis papilla is covered with a nucleate epithelium and projects into a spacious male atrium. The latter shows a distinct constriction before communicating with the common atrium, a female atrium virtually being absent. In turn, the common atrium is provided with a valve or fold just before it connects with the gonopore. Male and common atrium are lined with a simple columnar, nucleated epithelium and are surrounded by a relatively thick coat of subepithelial circular muscle. In addition, male and common atrium are surrounded by a broad zone of thick and loosely arranged longitudinal muscle fibres (Fig. 9). Notably around the male atrium these strong longitudinal muscle fibres are arranged in a ball-shaped zone. However, some of these muscles extend also well over the common atrium, attaching around the gonopore (Fig. 10).

A nucleated bursal canal arises from the common atrium, curves over the ball-shaped mass of muscle around the male atrium and subsequently communicates with a sac-shaped copulatory bursa that lies directly in front of the penis bulb. The bursa contains remnants of a spermatophore; a ruptured spermatophore projects also out of the gonopore of specimen V.Pl. 3055.1 (Fig. 11). The bursal canal is covered by a layer of circular muscle and receives the openings of shell glands well below the point where the oviducts open separately into the canal.

Discussion.- Although the presumed apomorphic characters for the Dugesiidae, the presence of multicellular pigment cups with numerous retinal cells (cf. Sluys, 1989, but see Baguna et al., 2001, Sluys, 2001 and Sluys and Kawakatsu, 2006 for a possible differ-

5

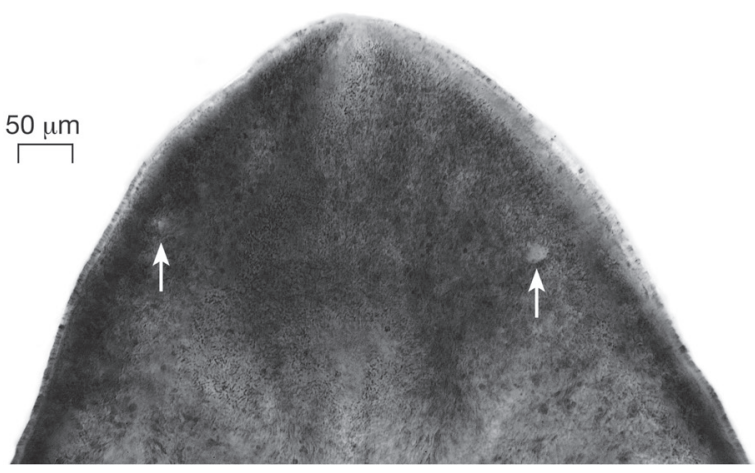

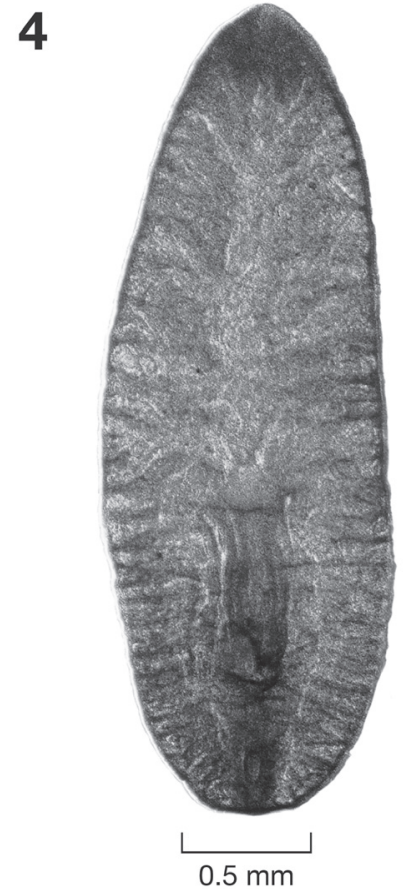

Fig. 4. Weissius capaciductus. ZMA V.P1. 3059.1. Dorsal view of whole mount.

ent perspective on these characters) cannot be assessed on $W$. capaciductus, the species cannot be placed in the Planariidae or the Dendrocoelidae since it clearly does neither possess a common oviduct opening into the atrium, nor does it show the dendrocoelid type of pharynx. Therefore, the species is here assigned to the Dugesiidae.

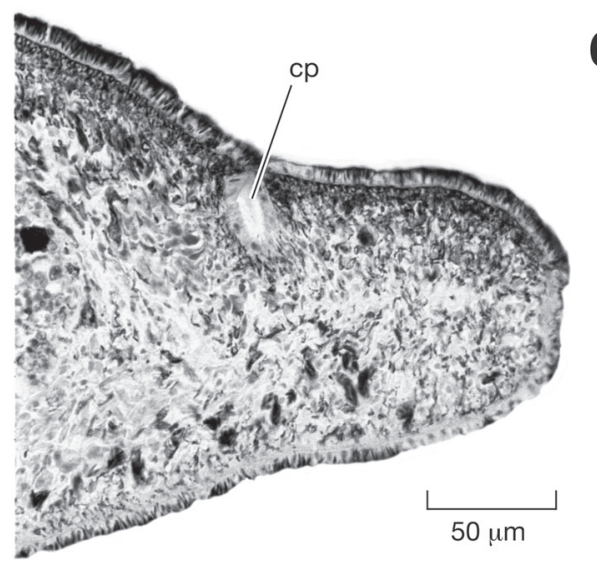

Figs. 5, 6. Weissius capaciductus. 5, ZMA V.P1. 3059.1. Dorsal view of head, showing the ciliated pits (indicated by arrows). 6, ZMA V.Pl. 3058.1. Microphotograph of ciliated pit. 


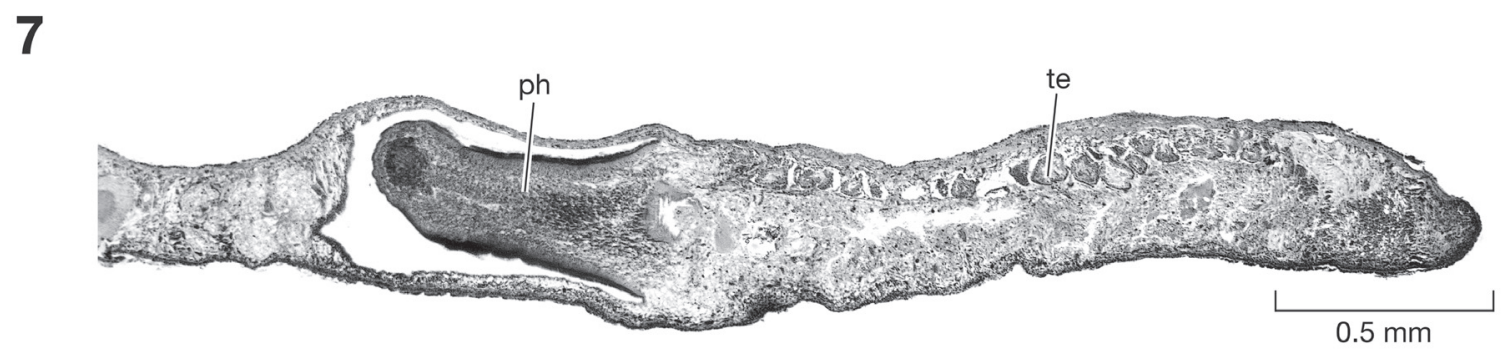

Fig. 7. Weissius capaciductus. Holotype. Microphotograph of sagittal section through testes. Anterior to the right.

Sluys (2001) pointed out and researched the problem that several of the current genera in the Dugesiidae lack adequate, phylogenetic diagnoses, thus complicating the taxonomic placement of new species. Subsequent to his cladistic analysis of a morphological dataset, incorporating all dugesiid species, Sluys (2001) explored possible diagnostic features of the current genera through manipulation of his preferred $50 \%$ majority rule consensus tree. Although the study did not formally publish new diagnoses for the various genera, because of its exploratory nature, it forms nevertheless the most recent and up-to-date reference point for the taxonomy of dugesiid genera.

Considering the taxonomy of dugesiid species and genera as expressed in Sluys' (2001, fig. 7.15) "guestimated" tree, we find it impossible (1) to synonymize $W$. capaciductus with one of the currently known species, and (2) to fit the new species comfortably within one of the current genera. Absence of a branched oviduct in $W$. capaciductus precludes assignment to Spathula, Eviella, and Reynoldsonia, while absence of a diverticulum makes it impossible to assign the species to Romankenkius. It does certainly not belong to Dugesia because it lacks the characteristic diaphragm of that genus. And neither does $W$. capaciductus show the double seminal vesicle that is characteristic for Schmidtea. The genera Neppia and Girardia are poorly defined from a phylogenetic point of view. However, in most species of Neppia the bursal canal is surrounded by a thick zone of circular muscle, which is absent in $W$. capaciductus. In contrast to W. capaciductus, many species of Girardia have a pigmented pharynx, while in Girardia species and also in aberrant Bopsula, the testes generally occur throughout the body.

An important feature in the taxonomy of dugesiid genera is the arrangement of the muscle layers around

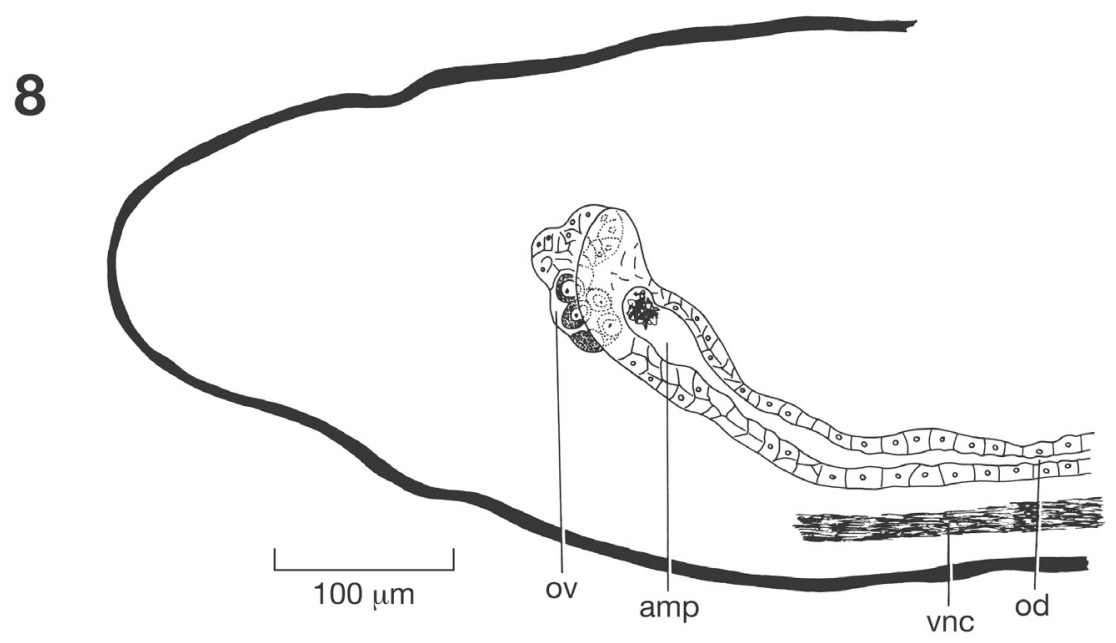

Fig. 8. Weissius capaciductus. Holotype. Sagittal reconstruction of ovary and oviducal ampulla. Anterior to the left. 
9

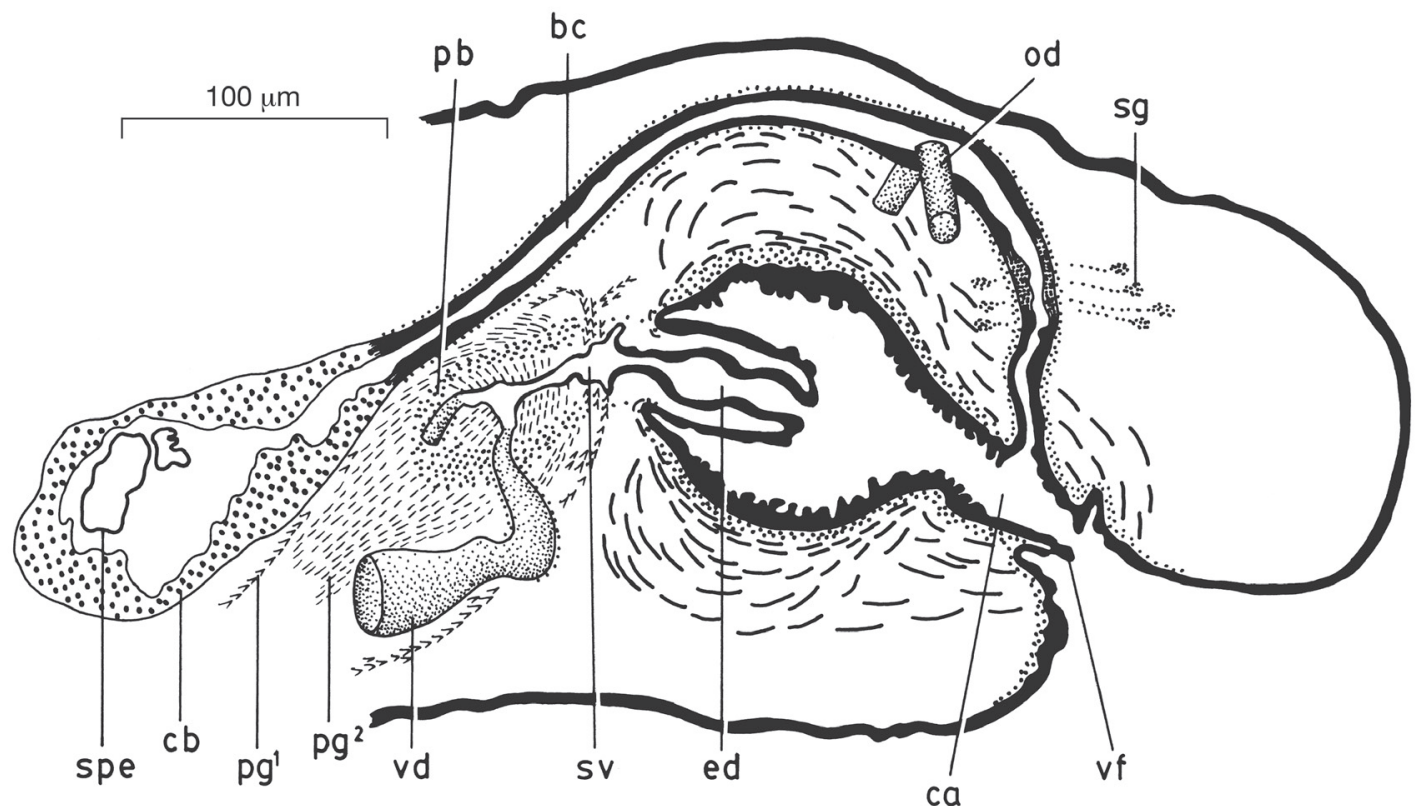

Fig. 9. Weissius capaciductus. Holotype. Sagittal reconstruction of the copulatory apparatus. Anterior to the left.

the bursal canal. In the non-reversed condition the bursal canal is surrounded by a subepithelial layer of circular muscle, followed by a layer of longitudinal muscle. In the reversed condition there is a subepithelial layer of longitudinal muscle, followed by a layer of circular fibres. For example, species of Spathula, Romankenkius, and Dugesia are generally characterized by a reversed musculature, whereas Girardia exhibits the non-reversed condition. However, the state of this particular phylogenetic and taxonomic character can- not be assessed in W. capaciductus since it merely possesses one layer of muscle around the bursal canal, viz. a circular muscle layer. A single zone of circular muscle around the bursal canal is known also from Cura pinguis (cf. Sluys and Kawakatsu, 2001). In addition, there are a few other features that suggest a close relationship between Weissius and Cura.

Sluys $(1997,2001)$ restricted the genus Cura to the species C. pinguis, C. foremanii, C. fortis, C. evelinae, and C. graffi. In another paper (Grant et al., 2006) it is
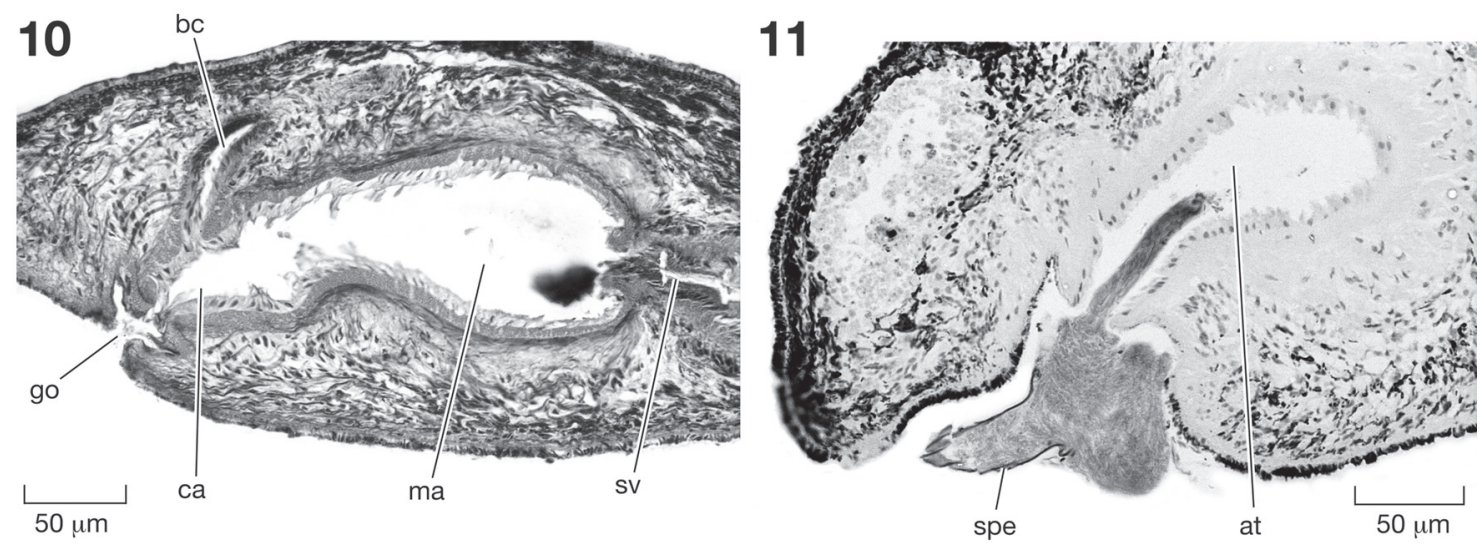

Figs 10, 11. Weissius capaciductus. 10, ZMA V.P1. 3057.1. Microphotograph showing musculature around atrium and gonopore. 11, AM W.29447. Microphotograph of spermatophore projecting out of gonopore. Anterior to the right. 
argued that $C$. graffi does not belong to Cura and the species is tentatively transferred to the genus Girardia. Weissius resembles the four remaining species of Cura in that all five have a finger- or thumb-shaped penis papilla as well as a male atrium that is set off from the common atrium and at the same time is surrounded by broad zones of circular and longitudinal muscle fibres. The last-mentioned, compound feature suggests that Weissius belongs to the clade that already comprised Cura and Schmidtea, since Sluys (2001) postulated this compound character regarding the male atrium as a synapomorphy for the two lastmentioned genera. Weissius may be more closely related to Schmidtea since it lacks the short common oviduct and particularly the anteriorly displaced point of communication between atrium and bursal canal that are characteristic features for species of Cura. Although Weissius may be taxonomically close to Schmidtea, it cannot be assigned to this genus because it lacks the double seminal vesicle and the mixed bursal canal musculature of the last-mentioned genus. Furthermore, in Schmidtea the testes are situated dorsally and occur throughout the body, in contrast to the conditions in Weissius. As a consequence, the combination of features present in $W$. capaciductus requires the erection of a new genus, albeit that it is difficult to describe apomorphic features that uniquely identify the genus.

\section{Biogeography}

This study is the first one dealing with the flatworm fauna of the artesian springs in Queensland since Sluys (1986) reported the first flatworm - from a completely different Order - from an artesian habitat in South Australia. The latter, Promacrostomum palum Sluys, 1986, turned out to be a unique species from a genus for which only two other species have been described, one living in Spain and Italy and the other in Lake Ohrid, former Yugoslavia. Presence of the Old World genus Dugesia in Australia was reported only relatively recently when Sluys et al. (1998) described D. notogaea Sluys and Kawakatsu, 1998 from localities in northern Queensland. Further records in the same region are detailed in Sluys and Kawakatsu (2001) and Grant et al. (2006), with the last-mentioned publication providing a distribution map of all published records. The Edgbaston locality from which the present paper describes the second species of Dugesia for Australia, is approximately
$245 \mathrm{~km}$ removed (almost directly south) from the nearest site that yielded Dugesia notogaea, viz. Porcupine Creek, Porcupine Gorge National Park, Hughenden, Queensland.

It is interesting to note that from the Edgbaston pools and springs also two new endemic fish species were described, viz. the goby Chlamydogobius squamigenus Larson, 1995 and the blue-eye Scaturiginichthys vermeilipinnis Ivantsoff, Unmack, Saeed and Crowley, 1991 (Ivantsoff et al., 1991; Larson, 1995).

Considering the distribution pattern of the genus (Fig. 12), one might entertain the idea that the ancestor of the present Dugesia species dispersed to Australia from Asia, probably some time during the Pleistocene, when sea levels were much lower. Freshwater planarians need contiguous freshwater bodies in order to be able to survive and disperse. However, paleogeographical reconstructions reveal that the river systems of Asia on the one hand and Australia/New Guinea on the other hand, have not been in contact during the Pleistocene (cf. Voris, 2000). This will have effectively prevented Dugesia to spread from Asia to New Guinea (where it is represented by the species $D$. novaguineana Kawakatsu, 1976) and Australia.

There are two options to explain the occurrence of Dugesia in Australia. One explanation could invoke jump dispersal, long-distance dispersal, which seems unlikely in view of the ecology of the animals. Second, if we look at the paleogeographical evolution of this area, one could hypothesize that future paleogeographical studies will show that during at least one period during the past 250.000 years, the river systems of Asia and Australia/New Guinea have been in contact with eachother, thus enabling Dugesia to spread from its Old World main massing onto the Australian craton. However, the latter hypothesis will not be considered favourably by most paleogeographers.

It is even more difficult to explain the occurrence of monotypic Weissius (Fig. 12) and the presumably closely related Cura pinguis (the sole representative of its genus on the Australian continent) in Australia. The latter occurs also in New Zealand and New Caledonia. Furthermore, other species of Cura are distributed in New Zealand (C. fortis), South Africa (C. evelinae), and the eastern half of North America ( $C$. foremanii). This extensive biogeographic track for the genus (cf. Grant et al., 2006, fig. 71) probably implies that Cura is an old group that radiated well before Pleistocene times. The same may apply to the presumably closely related Weissius. 


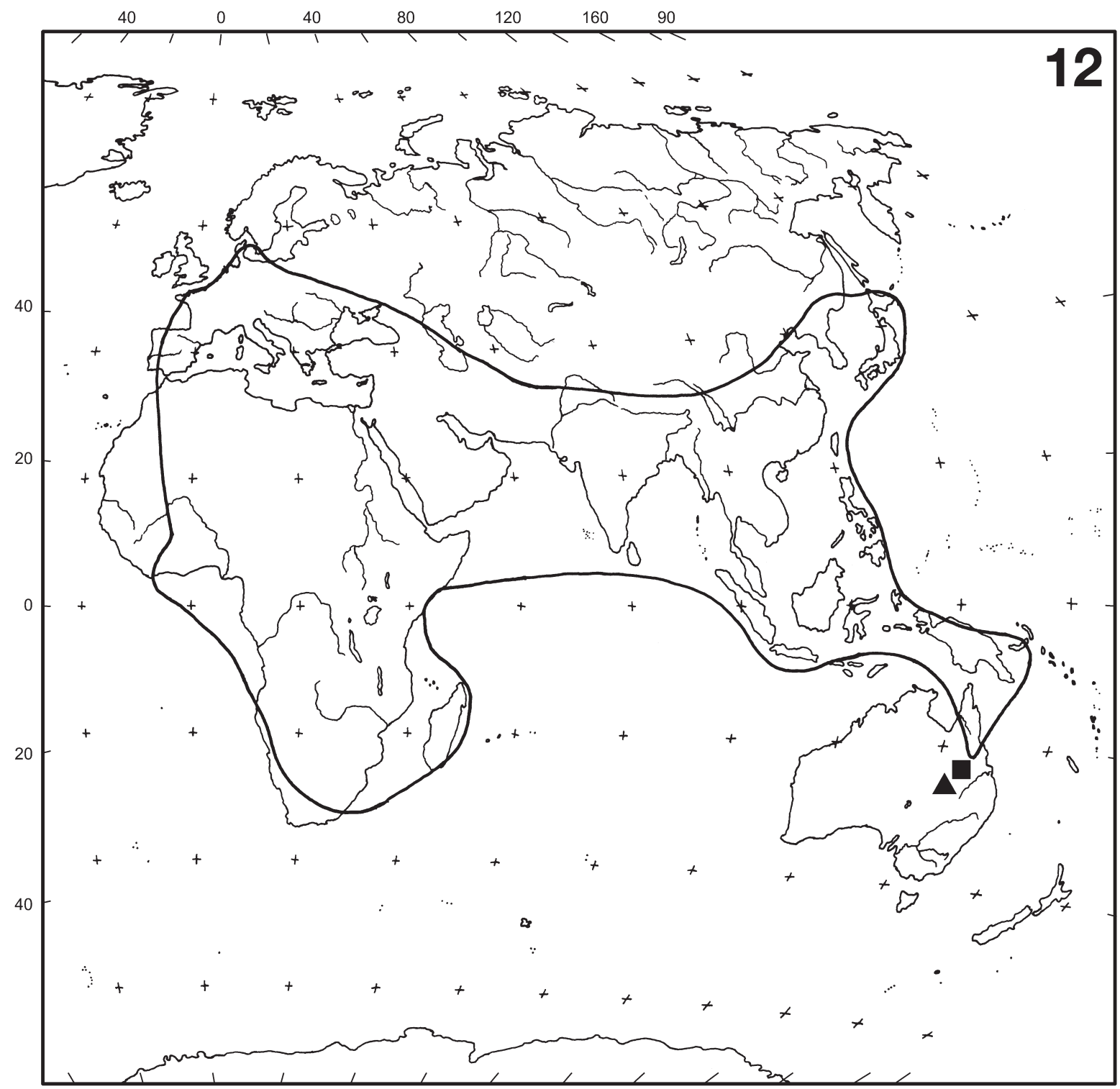

Fig. 12. Distribution of the genus Dugesia (extent of known range indicated by continuous line; after Sluys et al., 1998), with the new localities for D. artesiana (rectangle) and W. capaciductus (triangle).

\section{Acknowledgements}

We are grateful to Dr. W.F. Ponder (Australian Museum, Sydney) for making available to us the flatworm samples and for providing information on the sampling localities. The work of LJG on the freshwater planarians of Australia was supported by an ABRS grant for the project "Biodiversity, biogeography, and phylogeny of Australian aquatic planarians (Platyhelminthes, Tricladida, Paludicola).” Mr. J. van Arkel (IBED, University of Amsterdam) is thanked for the digitial rendering of the illustrations.

\section{References}

Baguñà J, Carranza S, Paps J, Ruiz-Trillo I, Riutort M. 2001. Molecular taxonomy and phylogeny of the Tricladida. In: Littlewood DTJ, Bray RA, eds., Interrelationships of the Platyhelminthes. London: Taylor \& Francis. Systematics Association Special Volume Ser. 60: 49-56.

Ball IR. 1974. A new genus of freshwater triclad from Tasmania, with reviews of the related genera Cura and Neppia (Turbellaria, Tricladida). Life Sciences Contribution Royal Ontario Museum 99: 1-48. 
Ball IR. 1977. A monograph of the genus Spathula (Platyhelminthes: Turbellaria: Tricladida). Australian Journal of Zoology, Suppl. Ser. 47: 1-43.

Ball IR, Tran, TV-H. 1979. New freshwater triclads from Tasmania (Platyhelminthes, Turbellaria). Bijdragen tot de Dierkunde 49: 153-161.

Bradbury P, Gordon K. 1977. Connective tissues and stains. In: Bancroft, JD, Stevens A, eds., Theory and Practice of Histological Techniques. London: Longman Group Ltd., 95-112.

Grant LJ, Sluys R, Blair D. 2006. Biodiversity of Australian freshwater planarians (Platyhelminthes, Tricladida, Paludicola): new species and localities, and a review of paludicolan distribution in Australia. Systematics and Biodiversity 4: 435-471.

Ivantsoff W, Unmack P, Saeed B, Crowley LELM. 1991. A redfinned blue-eye, a new species and genus of the family Pseudomugilidae from central Western Queensland. Fishes of Sahul 6: 277-282.

Larson HK. 1995. A review of the Australian endemic gobiid fish genus Chlamydogobius, with description of five new species. The Beagle 12: 19-51.

Ponder WF, Clark GA. 1990. A radiation of hydrobiid snails in threatened artesian springs in western Queensland. Records of the Australian Museum 42: 301-363.

Ponder WF, Hershler R, Jenkins B. 1989. An endemic radiation of hydrobiid snails from artesian springs in northern South Australia: their taxonomy, physiology, distribution and anatomy. Malacologia 31: 1-140.

Sluys R. 1986. First representative of the Order Macrostomida in Australia (Platyhelminthes, Macrostomidae). Records of the South Australian Museum 19: 399-404.

Sluys R. 1989. Phylogenetic relationships of the triclads (Platyhelminthes, Seriata, Tricladida). Bijdragen tot de Dierkunde 59: $3-25$.

Sluys R. 1997. An old problem in a new perspective: the enigmatic evolutionary relationships of some Australian freshwa- ter planarians (Platyhelminthes, Tricladida, Paludicola). $\mathrm{Ca}$ nadian Journal of Zoology 75: 459-471.

Sluys R. 2001. Towards a phylogenetic classification and characterization of dugesiid genera (Platyhelminthes, Tricladida, Dugesiidae): A morphological perspective, In: Littlewood DTJ, Bray RA, eds., Interrelationships of the Platyhelminthes. London: Taylor \& Francis. Systematics Association Special Volume Ser. 60: 57-73.

Sluys R, Kawakatsu M. 2001. Contribution to an inventory of the freshwater planarians of Australia and New Zealand (Platyhelminthes, Tricladida, Dugesiidae), with distribution maps of the species examined. Beaufortia 51: 163-198.

Sluys R, Kawakatsu M. 2006. Towards a phylogenetic classification of dendrocoelid freshwater planarians (Platyhelminthes): a morphological and eclectic approach. Journal of Zoological Systematics and Evolutionary Research 44: 274284.

Sluys R, Kawakatsu M, Winsor L. 1998. The genus Dugesia in Australia, with its phylogenetic analysis and historical biogeography (Platyhelminthes, Tricladida, Dugesiidae). Zoologica Scripta 27: 273-289.

Voris HK. 2000. Maps of Pleistocene sea levels in Southeast Asia: shorelines, river systems and time durations. Journal of Biogeography 27: 1153-1167.

Weiss A. 1909. Turbellaria, Rhabdocoelida und Tricladida paludicola. In: Michaelsen W, Hartmeyer R, eds., Die Fauna Südwest Australiens: Ergebnisse der Hamburger südwestaustralischen Forschungsreise 1905 (Volume 2). Jena: Verlag von Gustav Fischer, 403-410.

Weiss A. 1910. Beiträge zur Kenntnis der australischen Turbellarien. I. Tricladen. Zeitschrift für wissenschaftliche Zoologie 94: 541-604.

Received: 31 May 2006

Accepted: 22 November 2006 
